\title{
Effectiveness of Child Care Policies in an Economy with Child Care Services
}

\author{
Masaya Yasuoka', Atsushi Miyake ${ }^{2}$ \\ ${ }^{1}$ Faculty of Economics and Business Administration, The University of Kitakyushu, Kitakyushu, Japan \\ ${ }^{2}$ Faculty of Economics, Kobe Gakuin University, Kobe, Japan \\ Email: yasuoka@kitakyu-u.ac.jp, miyake@eb.kobegakuin.ac.jp
}

Received June 28, 2012; revised July 25, 2012; accepted August 4, 2012

\begin{abstract}
This paper describes how fertility is determined in a model that assumes the existence of child-care services. When child-care services exist, two multiple states result: a state that brings about low fertility with low female labor participation, and a state that brings about high fertility with high female labor participation. This result is consistent with the positive correlation that is found between the total fertility rate and female labor participation in developed countries, as described by Ahn and Mira (2002) [1] and others. Moreover, this paper presents analyses of the effects of child-care policies, for example, a child allowance and a subsidy for child-care services policies. These policies instantaneously raise fertility. However, in a dynamic general equilibrium model, these policies might pull down fertility because capital accumulation decreases in the long run. If income growth continues in the long run, then the child allowance can always pull up fertility. However, if the income level converges to constant level in the long run, then the child allowance might pull down fertility. This result shows that the effect of the child allowance depends on whether income growth ceases or continues in the long run.
\end{abstract}

Keywords: Child-Care Policies; Child-Care Services; Fertility Rate; Labor Participation

\section{Introduction}

We find three positive correlations in developed countries: fertility and female labor participation, fertility and income per capita, and fertility and the magnitude of governmental family policy. First, the analyses described in this paper demonstrate the positive correlation between fertility and female labor participation.

As described by Ahn and Mira (2002) [1], Sleebos (2003) [2], and Yamaguchi (2005) [3], the correlation between fertility and female labor participation in developed countries was negative in the 1980s (cross-country compareson). However, that negative correlation has weakened gradually. In recent years, the correlation has changed to a positive one. One explanation for the change in the correlation from negative to positive is the enrichment of childcare services. Figure 1 presents the female labor participation rate and total fertility rate in developed countries. As Sleebos (2003) [2] and others point out, it is apparent that the higher the female labor participation rate is, the

\footnotetext{
${ }^{1}$ It is necessary to consider that the difference of female labor participation is related to labor market factors as well. Kögel (2004) [4] considered country-specific factors and country-heterogeneity and derived the negative correlation between fertility and female labor participation. Engelhardt and Prskawetz (2004) [5] identified variables indicating country heterogeneity.
}

higher the fertility rate is ${ }^{1}$.

By virtue of child-care services, parents need not pay an opportunity cost for children. Even if parents have children, they can continue working. Thereby, they gain wage income and can yet afford to have more children. Compatibility between child-care and working is the reason that the negative correlation between fertility and female labor participation is weakened and changes to a positive correlation.

Galor and Weil (1996) [6] set a theoretical model incorporating a gender gap in the wage rate and derived a

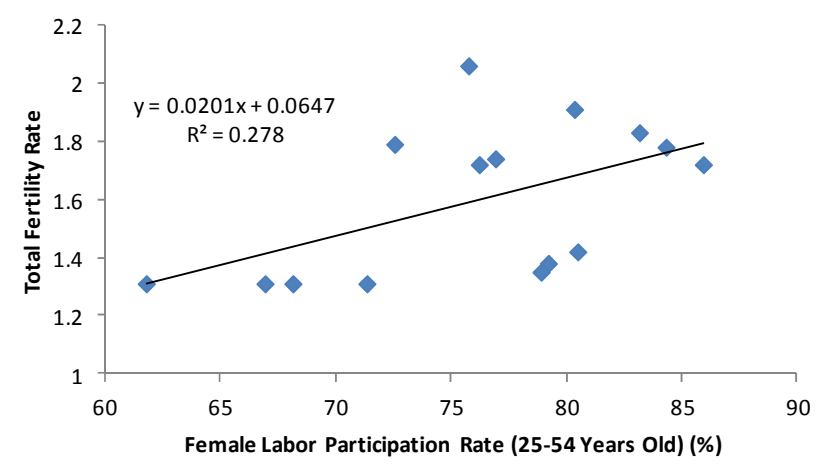

Figure1. Positive correlation between total fertility rate and female labor participation. 
negative correlation between fertility and the female labor participation rate. An increase in the female labor wage pulls up the labor supply. Therefore, fertility decreases. Apps and Rees (2004) [7] introduced child-care services, which can produce compatibility between child care and working, and derived a positive correlation. Apps and Rees (2004) [7] assumed a fertility function into which a parent's child care and market child-care services are inputted; it gives constant returns to scale. Hirazawa and Yakita (2009) [8] specified an elasticity between a parent's childcare time and market child-care services and derived fertility dynamics for a small open economy.

Martínez and Iza (2004) [9] analyzed how fertility is determined under the assumption of complete substitution between a parent's child care and market child-care services in a dynamic general equilibrium model and derived a positive correlation between fertility and female labor participation. Yasuoka (2008) [10] assumed a constant elasticity of substitution (CES) fertility function, which is determined by the parent's child care and market child-care services. Some studies assumed a different fertility function $^{2}$.

Martínez and Iza (2004) [9] insisted that an increase in the skill premium decreases fertility directly; however, market child-care services not only prevent a decrease in fertility but also bring about a positive relation between fertility and the skill premium (capital per capita, labor participation).

Galor and Weil (1996) [6] described that an increase in the skill premium decreases fertility because of the absence of market child-care services ${ }^{3}$. Consequently, with market child-care services considered by Apps and Rees (2004) [7] or Martínez and Iza (2004) [9] in the model economy presented by Galor and Weil (1996) [6], a positive relation is apparent between fertility and female labor participation.

Second, this paper considers the positive correlation between fertility and income per capita. The positive correlation in developed countries is confirmed to exist between total fertility and income per capita, as shown in Figure 2.

Aarssen (2005) [13] showed a negative correlation between fertility and income per capita in 223 countries, including both developed and developing countries. This negative correlation is natural because the infant mortality rate is high and parents typically consider children as insurance or investment goods in low-income countries.

\footnotetext{
${ }^{2}$ For example, Momota (2000) [11] assumed a fertility function by which child care by both men and women in addition to governmental service determines fertility. Yasuoka (2007) [12] considered the fertility function, which is determined using a parent's child care and governmental services. ${ }^{3}$ Capital accumulation pulls up the wage rate in skilled sector. In Galor and Weil (1996) [6], capital accumulation is described as pulling up the wage rate of female laborers, which shrinks wage inequality between men and women. An increase in the skill premium corresponds to shrinking wage inequality between men and women.
}

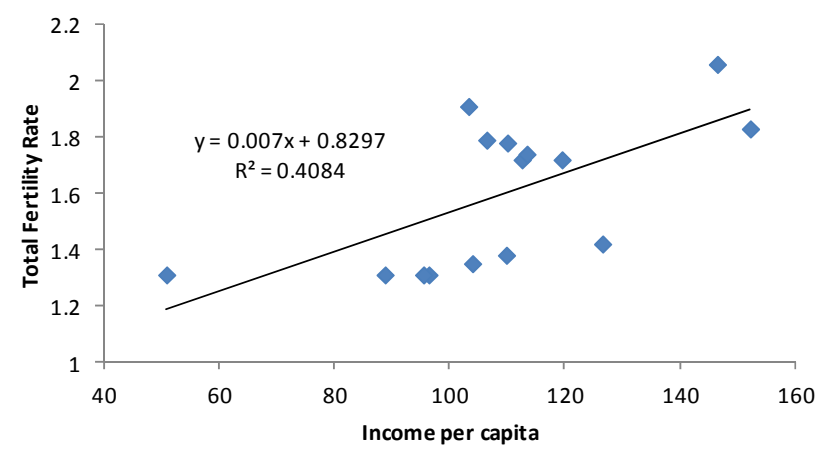

Figure 2. Positive correlation between total fertility rate and income per capita.

Confronting a poor social security system, parents depend on their children in their old age. However, in economically developed countries, which have high income per capita, because of the social security system, parents need not depend on children. Other reasons are that child-care costs are high (Educational costs or opportunity costs for child care ${ }^{4}$ ) or that parents want to increase the quality of life by decreasing the number of children they plan to have. However, Figure 2 shows the positive correlation between fertility and income per capita in developed countries. This fact is consistent with theoretical analyses in a market child-care service model (Apps and Rees (2004) [7], Martínez and Iza (2004) [9], Hirazawa and Yakita (2009) [8]). Models that do not consider market child-care services explicitly show a positive correlation (Oshio (2001) [18], van Groezen, Leers and Meijdam (2003) [19], van Groezen and Meijdam (2008) [20], Fanti and Gori (2009) [21], and others).

Third, this paper presents examination of the positive correlation between fertility and the magnitude of governmental family policy.

Although market child-care services play an important role in an increase in the fertility, family policy plays an important role in raising fertility, too. McDonald (2006) [22] surveyed some earlier papers that examined family policy. Some earlier papers showed that financial incentives can be effective for increasing fertility (Lutz (1999) [23], Milligan (2002) [24], Laroque and Salanie (2005) [25]). In fact, a positive correlation is shown between the fertility and the magnitude of family policy in developed countries, as depicted in Figure 3.

This paper describes analyses of the degree to which and the manner in which fertility is affected by market childcare services and child-care policy, using a model that assumes complete substitution between individual child care and child-care services, as in Martínez and Iza (2004) [9].

\footnotetext{
${ }^{4}$ Becker (1960) [14] set the quality and quantity of children model and derived an increase in income raises the quality and decreases quantity because of an opportunity cost. Becker, Murphy, and Tamura (1990) [15], de la Croix and Doepke (2003) [16] and Kimura and Yasui (2009) [17] considered the quality of children as reflected in educational investment for children.
} 


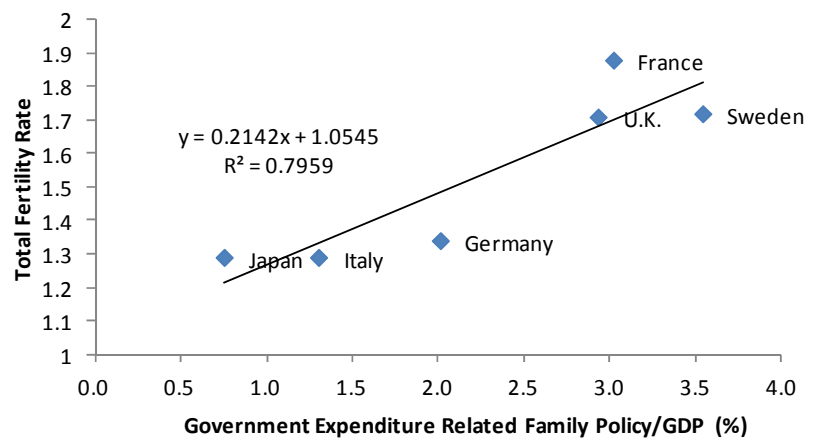

Figure 3. Child-care support policy and the total fertility rate $^{5}$.

This paper presents the following results. Given some parametric conditions, the existence of market child-care services, which rich households consume, brings about one of two states: 1) A state of low-fertility equilibrium with low female labor participation, low income and high income growth; or 2) A high-fertility equilibrium with high female labor participation and high income (and low income growth).

Without market child-care services, one steady state exists with low fertility, low female labor participation and high income growth. Therefore, fertility remains at a low level.

However, with market child-care services, the steady state changes to one with high fertility, high female labor participation and low income growth (or high income with no income growth). Therefore, market child-care services raise the fertility and female labor participation rate, which indicates a positive correlation between fertility and female labor participation.

Zhang (1997) [26] set the model with quality and quantity of children. With a small cost for increase in quantity of children, the equilibrium with high fertility and low income growth rate is derived. Quality and quantity of children show a negative relation between fertility and the income growth rate; our paper derived a negative relation without quality and quantity of children.

In the latter part of this paper, we present analysis of whether child-care policies (e.g., a child allowance policy-households receive an allowance in proportion to the

${ }^{5}$ Data: OECD Database (OECD Stat Extracts) (OECD), Demographic Yearbook (UN) and Vital Statistics in Japan (Ministry of Health, Labour and Welfare (in Japan)). The Fertility in Figures $\mathbf{1}$ and $\mathbf{2}$ an average level for 2000-2007. The female labor participation rate (25 - 52 years old) in Figure 2 is an average level for 2000-2007. The income per capita in Figure 2 is an average level for 2000-2007. The OECD average income per capita is fixed as 100. Figures $\mathbf{1}$ and $\mathbf{2}$ show data for Australia, Austria, Denmark, France, Germany, Hungary, Italy, Japan, Netherlands, Norway, Spain, Sweden, Switzerland, the United Kingdom, and the United States.

Government Expenditure Related Family Policy per GDP in Figure $\mathbf{3}$ is at 2003 and includes a family allowance, maternity and parental leave, other cash benefits, day-care, home-help and other benefits in kind. Fertility in Figure 3 is at 2003. number of children they have-or a subsidy for childcare services) can raise the fertility rate.

As presented in Figure 3, an active child-care policy brings about a high fertility rate. This paper shows that the effects of child-care policies differ in the short run and in the long run. In the short run, a rise in fertility increases the labor supply in the subsequent period, resulting in the decrease of income in the subsequent period because accumulation of capital per capita is prevented. Therefore, in the long run, fertility does not always increase because of the fall in income. This paper shows that the child allowance does not always raise fertility. However, if income growth continues in the long run, then a child allowance can always raise fertility. If income converges to a steady state with constant income, the child allowance can not always raise fertility, which conclusions are closely consistent with those reported by Fanti and Gori (2009) [21]; however, with continued income growth, the effects of a child allowance differ from those described by Fanti and Gori (2009) [21]. In summary, child-care support policies can raise fertility in the short run, but the long-run effects of the policies are unclear. The dynamic general equilibrium model brings about results that demonstrate that the government must consider effects of child-care policies in the short run as well as in the long run before implementing them.

This paper is structured as follows. Section 2 explains our model setting. Section 3 provides a description of the dynamic equilibrium. Section 4 analyzes the child-care policy. Section 5 presents examination of a case in which a child-care service fee depends on the wage rate. The final section presents concluding remarks.

\section{The Model}

The model economy in this paper is constructed in terms of a two-period (young and old) overlapping generations model. The economy comprises agents of three types: households, firms, and the child-care service sector. We explain the agents in the following subsections.

\subsection{Households}

Individuals in households live in two periods: young and old $^{6}$. Each household supplies labor and gains labor income only during the young period, when individuals raise their children. The analyses described herein assume that it is necessary for households (parents) to input their childcare time and child-care goods to have children. Households have one unit of time, which is assumed to be allocated to labor and child care. However, for these analyses, we assume that child-care services exist. If households

\footnotetext{
${ }^{6}$ Strictly speaking, individuals in this model live three periods: childhood young, and old. However, individuals do nothing during childhood. Therefore, we consider this model as substantially a two-period model.
} 
pay a fee to use child-care services, then the child-care time per child will decrease to zero and they can work full time. Each individual distributes labor income across child-care goods and consumption during young and old periods. We obtain the following budget constraint if households do not use child-care services:

$$
\mathrm{zn}_{t}+c_{1 t}+\frac{c_{2 t+1}}{1+r_{t+1}}=\left(1-\phi n_{t}\right) w_{t}, 0<\phi<1,
$$

where $n_{t}$ represents the number of children; $c_{1 t}$ and $c_{2 t+1}$ respectively denote consumption by young and old generations; $r_{t+1}$ and $w_{t}$ respectively represent the interest rate and wage rate; and $t$ represents the period. It takes $\phi$ units of time to raise one child. Furthermore, the parents must buy some child-care goods $z$ for their child ${ }^{7}$. Therefore, the child-care cost per child is $z+\phi w_{t}$. The higher the wage rate $w_{t}$ is, the higher is the marginal cost to have a child.

In contrast, households using child-care services must pay a fee $p$. Therefore, the necessary child-care time per child decreases and changes to zero ${ }^{8}$. Households with $n_{t}$ children can supply a unit of labor. We can consider 1 $\phi n_{t}$ as a couple's or a female's labor participation rate ${ }^{9}$. Then, by virtue of child-care services, the female labor participation rate rises from $1-\phi n_{t}$ to 1 (by $\phi n_{t}$ ). In this case, we obtain the following budget constraint:

$$
(z+p) n_{t}+c_{1 t}+\frac{c_{2 t+1}}{1+r_{t+1}}=w_{t}
$$

Having $n_{t}$ children, the child-care cost is $(z+p) n_{t}$. If the child-care cost per child in the case in which households use child-care services is less than that in the case in which they do not, then they use child-care services. This condition can be represented as $z+\phi w_{t}>z+p$, i.e.,

$$
\phi w_{t}>p \text {. }
$$

Households use child-care services if this condition is satisfied.

\footnotetext{
${ }^{7}$ van Groezen, Leers and Meijdam (2003) [19] introduced the survey on measurement of the cost of children by Praag and Warnaar (1997) [27]. As in the analysis by van Groezen, Leers and Meijdam [19], this paper considers $z$ as the quality of a child, which reflects the consumption of food, clothing, education, and so on.

${ }^{8}$ Martínez and Iza (2004) [9] assumed that parents need no time for having children if they use child-care services, too.

${ }^{9}$ Apps and Rees (2004) [7] considered labor of two types: labor supplied using a working husband and labor supplied using a wife, a female homemaker. They assumed that a worker supplies a unit of labor inelastically and that a female homemaker supplies labor net of the child-care time. They considered the labor supply offered using a female homemaker as the female labor participation rate. Then, the couple's labor supply becomes $2-\phi n_{t}$ because the male supplies a unit of time and the female supplies $1-\phi n_{t}$ unit of time. However, we assume the couple's time as one. Therefore, the couple's labor time is $1-\phi n_{t}$. This assumption does not affect the following results. If we assume that the labor is supplied inelastically by a male worker, as described in earlier studies, then we can consider $1-\phi n_{t}$ as the female labor participation rate.
}

The households' utility function $u_{t}$ is assumed as

$$
\begin{aligned}
& u_{t}=\alpha \ln c_{1 t}+\beta \ln c_{2 t+1}+(1-\alpha-\beta) \ln n_{t}, \\
& 0<\alpha, \quad \beta<1, \quad \alpha+\beta<1
\end{aligned}
$$

It is assumed that households gain utility not from their children's lifetime utility but simply by having children $^{10}$.

Next, we consider the optimization problem in two cases: 1) The case in which households use child-care services; and 2) The case in which they do not use these services.

\subsubsection{Case in Which Households Do Not Use Child-Care Services}

Each household maximizes its utility (4) under the budget constraint (1). We therefore obtain the following optimum equation:

$$
\begin{gathered}
c_{1 t}=\alpha w_{t} \\
c_{2 t+1}=\left(1+r_{t+1}\right) \beta w_{t} \\
n_{t}^{\text {no }}=\frac{(1-\alpha-\beta) w_{t}}{z+\phi w_{t}}
\end{gathered}
$$

where $n_{t}^{\text {no }}$ denotes the number of children in the case in which each household uses no child-care services. We assume the child-care cost $z$ as $z \equiv \hat{z} w_{t} \quad(\hat{z}>0$ is parameter) ${ }^{11}$. Then, $n_{t}^{\text {no }}$ is derived as

$$
n_{t}^{\text {no }}=\frac{(1-\alpha-\beta)}{\hat{z}+\phi}
$$

An increase of the child-care cost in $\hat{z}$ or $\phi$ pulls down the fertility $n_{t}^{\text {no }}$. Even if the wage rate $w_{t}$ rises, then the fertility $n_{t}^{\text {no }}$ does not increase because an increase in the wage rate raises child-care cost $z$ and the opportunity cost for children $\phi w_{t}$.

\subsubsection{Case in which Households Use Child-Care Services}

Each household maximizes its utility (4) under the budget constraint (2). Although optimal consumption allocation $c_{1 t}, c_{2 t+1}$ is the same as the allocation in the case in which households do not use child-care services, $n_{t}$ differs from this case. The number of children (fertility) in this case $n_{t}^{\text {care }}$ is shown as

$$
n_{t}^{\text {care }}=\frac{(1-\alpha-\beta) w_{t}}{\hat{z} w_{t}+p}
$$

Then, $n_{t}=n_{t}^{\text {care }}$ in $\phi w_{t}>p$. Otherwise, $n_{t}=n_{t}^{\text {no }}$.

\footnotetext{
${ }^{10}$ This assumption is conventional in the endogenous fertility model and is identical to that described in Eckstein and Wolpin (1985) [28], Galor and Weil (1996) [6], van Groezen, Leers, and Meijdam (2003) [19], and others.

${ }^{11}$ This paper assumes that child-care cost $z$ increases concomitantly with an increase in the wage rate $w_{t}$. This child-care cost, which is pulled up by an increase in wage income, is assumed in van Groezen and Meijdam (2008) [20] and Wigger (1999) [29].
} 


\subsection{Firms}

We assume that the representative firms that have constant returns to scale production function can be represented as

$$
\begin{aligned}
Y_{t}^{i}= & F\left(K_{t}^{i}, B_{t} L_{t}^{i}\right), \frac{\partial Y_{t}^{i}}{\partial K_{t}^{i}}>0, \\
& \frac{\partial Y_{t}^{i}}{\partial B_{t} L_{t}^{i}}>0, \frac{\partial^{2} Y_{t}^{i}}{\partial K_{t}^{i 2}}<0, \frac{\partial^{2} Y_{t}^{i}}{\partial B_{t} L_{t}^{i 2}}<0,
\end{aligned}
$$

where $Y_{t}^{i}$ denotes the firm $i$ 's output and $K_{t}^{i}$ and $L_{t}^{i}$ respectively signify firm $i$ 's capital stock and labor. In addition, $B_{t}$ represents labor productivity, which is equal among firms and which is assumed as

$$
B_{t}=\frac{K_{t}}{L_{t}} \frac{1}{b}, b>0
$$

Labor productivity $B_{t}$ is dependent on the capital per labor input, which is also assumed in Romer (1986) [30] and Grossman and Yanagawa (1993) [31]. Therein, $K_{t}$ and $L_{t}$ respectively represent aggregate capital stock and aggregate labor input. In a perfectly competitive market, considering the symmetry of firms, wage $w_{t}$ and capital rent $r_{t}$ are equal to the marginal product of each factor input.

$$
\begin{gathered}
w_{t}=B_{t}\left(f(b)-f^{\prime}(b) b\right) \\
1+r_{t}=f^{\prime}(b)
\end{gathered}
$$

We assume that the capital stock fully depreciates within a period. If we define $\omega \equiv f(b)-f^{\prime}(b) b$, then the wage rate shown by (11) is

$$
w_{t}=\frac{\omega}{b} \frac{K_{t}}{L_{t}}
$$

Defining $N_{t}$ as the population size of young people in $t$ period, $L_{t}=\left(1-\phi n_{t}\right) N_{t}$ unless households use child-care services, or $L_{t}=N_{t}$ if they use it.

\subsection{Child-Care Service Sector}

The child-care service sector supplies child-care services and receives a fee of $p$ per child, which is paid by the parents. It establishes child-care facilities to provide childcare services. Originally, in considering the provision of child-care services, we assume that it costs $c$ units of final goods to provide child-care services for each child. Martínez and Iza (2004) [9] assume that child-care services are produced by unskilled labor input. However, Hirazawa and Yakita (2009) [8] report that child care is produced by inputting market labor as well as market good labor.

\footnotetext{
${ }^{12}$ Martínez and Iza (2004) [9] assume that child-care service is produced by linear production technology, which has constant marginal cost. As Martínez and Iza (2004) [9] report, the child-care service price is constant. However, Yasuoka and Miyake (2010) [32] describe that demand and supply for child-care services affect child-care service prices in a different model.
}

We assume that child-care services are produced using the latter technology. Then, total revenue is $p n_{t} N_{t}$ and the total expenditure is $c n_{t} N_{t}$. Therefore, assuming profit maximization in a competitive market, we obtain $p=c^{12}$. Furthermore, $c$ is constant and is measured in terms of market goods.

\section{Equilibrium}

Having considered the agents' behavior, we proceed to analysis of the equilibrium. The equilibrium of this economy depends on the amount of capital-per-capita $\left(\equiv K_{t} / N_{t}\right)$. Representing the savings per household as $s_{t}$, the capital market clearing condition is given as $K_{t+1}=N_{t} s_{t}$, i.e., $n_{t} k_{t}$ ${ }_{+1}=s_{t}{ }^{13}$. In the following subsections, we derive equilibria for the case in which child-care services are available and for the case in which these services are not available.

\subsection{Equilibrium in No Child-Care Service}

In the absence of child-care services, labor supply $L_{t}$ is given as $L_{t}=\left(1-\phi n_{t}\right) N_{t}$. Considering the capital market equilibrium condition $k_{t+1}=s_{t} / n_{t}$ and the saving per household $s_{t}=\left(1-\phi n_{t}\right) w_{t}-c_{1 t}-z n_{t}, \quad z \equiv \hat{z} w_{t}$, $L_{t}=\left(1-\phi n_{t}\right) N_{t}$, (8) and (14), we obtain the following difference equation for $k_{t}$ :

$$
k_{t+1}=\frac{\beta \omega(\hat{z}+\phi)^{2}}{(1-\alpha-\beta) b(\hat{z}+(\alpha+\beta) \varphi)} k_{t}
$$

Then, with the defined income per capita as $y_{t}$, the growth rate of income per capita $g_{t} \equiv y_{t+1} / y_{t}=k_{t+1} / k_{t}$ is ${ }^{14}$

$$
g_{t}=\frac{k_{t+1}}{k_{t}}=\frac{\beta \omega(\hat{z}+\phi)^{2}}{(1-\alpha-\beta) b(\hat{z}+(\alpha+\beta) \phi)}
$$

We assume that $g_{t}>1$, i.e., $\beta \omega(\hat{z}+\omega)^{2} /((1-\alpha-\beta) b(\hat{z}+(\alpha+\beta) \phi))>1$. Then, the fertility in this case is given as (8). In this case, both the growth rate of income per capita and fertility are constant over time.

\subsection{Equilibrium in Child-Care Service}

Each household uses child-care services if condition (3) holds. Then, labor supply $L_{t}$ is given as $L_{t}=N_{t}$. With $k_{t+1}=s_{t} / n_{t}$ and the saving per household $s_{t}=w_{t}-c_{1 t}-z n_{t}$, $z \equiv \hat{z} w_{t}$, (9) and (14), we obtain the following difference equation for $k_{t}$ :

$$
k_{t+1}=\frac{\beta}{1-\alpha-\beta}\left(p+\frac{\hat{z} \omega}{b} k_{t}\right) .
$$

\footnotetext{
${ }^{13}$ We notify $n_{t}=N_{t+1} / N_{t}$.

${ }^{14}$ With (10) and constant returns to scale, we obtain $Y_{t} / N_{t}=K_{t} f(b) / N_{t}$, i.e., $y_{t}=f(b) k_{t}$. Therefore, $y_{t+1} / y_{t}=k_{t+1} / k_{t}$. We consider $k_{t+1} / k_{t}$ as the growth rate of income per capita.
} 
Then, the fertility is shown as

$$
n_{t}^{\text {care }}=\frac{1-\alpha-\beta}{\hat{z}+\frac{b p}{\omega k_{t}}},
$$

We consider steady states of two types: one for the steady state defined by the constant growth rate of income per capita and the other for that defined by constant capital per capita (income per capita) over time. With (17), $g_{t}=k_{t+1} / k_{t}$ is given as

$$
g_{t}=\frac{k_{t+1}}{k_{t}}=\frac{\beta}{1-\alpha-\beta}\left(\frac{p}{k_{t}}+\frac{\hat{z} \omega}{b}\right)
$$

If $k_{t} \rightarrow \infty$, then the growth rate becomes

$$
g=\frac{\beta}{1-\alpha-\beta} \frac{\hat{z} \omega}{b} .
$$

where g denotes the growth rate in $k_{t} \rightarrow \infty$. We define $n^{\text {care, }}$ growth as the fertility in constant growth rate $g$. Then, $n^{\text {care, }}$ growth is derived as

$$
n^{\text {care,growth }}=\frac{1-\alpha-\beta}{\hat{Z}} .
$$

To obtain this steady state, $\beta \hat{z} \omega /(b(1-\alpha-\beta))>1$ must hold. If $\beta \hat{z} \omega /(b(1-\alpha-\beta))<1$, then the growth of income per capita ceases in the long run, which brings about a steady state of the other type. This steady state is specified by $k_{t+1}=k_{t}=k$, where $k$ is the capital per capita at the steady state. Defining $n^{\text {care, nogrowth }}$ as fertility in this case, in this steady state, capital per capita $k$ and the fertility $n^{\text {care, nogrowth }}$ are given as

$$
\begin{gathered}
k=\frac{\beta b p}{(1-\alpha-\beta) b-\beta \hat{\mathrm{z}} \omega}, \\
n^{\text {care,nogrowth }}=\frac{\beta \omega}{b} .
\end{gathered}
$$

Concluding the dynamics of $k_{t}$, Figure 4 is depicted as shown below.

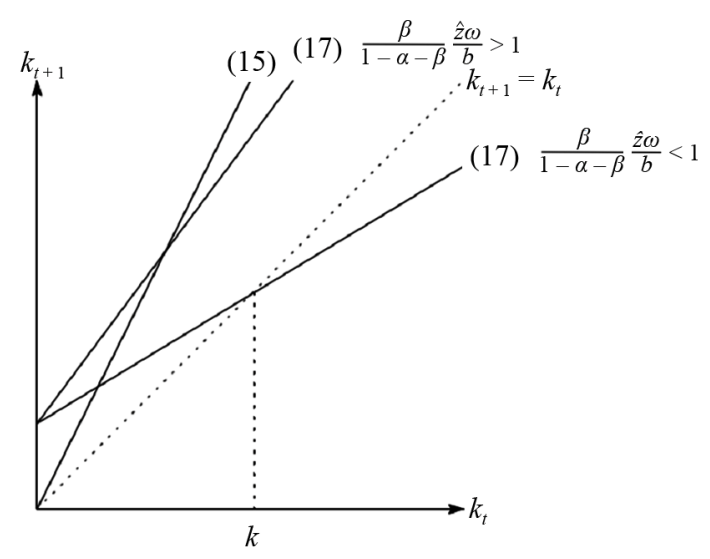

Figure 4. Dynamics of $k t$.
With condition (3), $n^{\text {no }}<n^{\text {care, nogrowth }}<n^{\text {care, growth15 }}$. Therefore, child-care services raise the fertility in the economy for which no child-care sector exists. In addition, even if growth of income per capita continues in the steady state with child-care service, then the growth rate in childcare service (20) is less than that in no child-care service $(16)^{16}$. Child-care service decreases the growth rate. With a large decrease in the growth rate, growth ceases and converges to constant capital per capita (22). Without childcare services, the opportunity cost for caring for children (parents must stop working to raise their children) prevents parents from choosing to have children. However, with child-care services, the opportunity cost vanishes and fertility increases. Therefore, it is readily apparent that capital-per-capita $k_{t+1}$ and the income growth rate $g_{t}$ decrease. A large decrease in $g_{t}$ halts income growth. Therefore, the following proposition is established.

\section{Proposition 1}

Introduction of child-care services increases fertility. However, it decreases the income-per-capita growth rate in the model economy in which no child-care sector exists.

Child-care services make child-care and working compatible: this proposition is an assertion that the countries which suffer from low fertility should carry out family policies that make child care and working compatible. Becker and Barro (1988) [33] and Barro and Becker (1989) [34] derived a negative correlation between fertility and the income growth rate. This proposition is consistent with Becker and Barro (1988) [33] and Barro and Becker (1989) [34] even if this model economy setting differs from those of Becker and Barro (1988) [33] and Barro and Becker (1989) [34] $]^{17}$.

We derived the equilibrium separately for each case. However, based on (3), households use child-care services. Considering (3) and (14), the condition in which households use child-care services is

$$
k_{t}>\frac{b p(\hat{z}+(\alpha+\beta) \phi)}{\omega \phi(\hat{z}+\phi)}
$$

We define $k$ as $\hat{k}=b p(\hat{z}+(\alpha+\beta) \phi) /(\omega \phi(\hat{z}+\phi))$. The dynamics of capital per capita (income growth rate) and the fertility in the equilibrium are given respectively as (15) and (8) because households do not use child-care services if $k_{t}<\hat{k}$. The dynamics of capital per capita (income growth rate) and the fertility in the steady state are given respectively as (17) and (18) if $k_{t}<\hat{k}$. Therefore, we obtain the steady state equilibrium presented in

\footnotetext{
${ }^{15}$ We notify $\beta \hat{z} \omega /(b(1-\alpha-\beta))<1 \quad$ in $n^{\text {care, nogrowth }}$.

${ }^{16}$ Subtracting (20) from (16), we obtain $(2-\alpha-\beta) \hat{z}+\phi>0$. The growth rate (20) is less than (16).

${ }^{17}$ Wang, Yip and Scotese (1994) [35] explained that the correlation between the growth rate of income per capita and population growth is ambiguous in empirical evidence; they examined the determinants of the sign.
} 


\section{Figure 5.}

Figure 5(a) shows the case of $\beta \hat{z} \omega /(b(1-\alpha-\beta))>1$. Considering the steady state characterized by constant income per capita growth rate $g$ and constant fertility over time, we obtain two states: one for a state that includes high income growth (or low income per capita), low fertility and low female labor participation; and the other for a state that has low income growth (or high income per capita), high fertility, and high female labor participation. Figure 5(b) shows the case of $\beta \hat{z} \omega /(b(1-\alpha-\beta))<1$. The dynamics of $k_{t}$ converges to constant income growth (20) and the fertility $n^{\text {care, growth }}$ (21) or constant income level (22) and the fertility $n^{\text {care, nogrowth }}$ (23). Then, the following proposition is established.

\section{Proposition 2}

Two states exist in this model economy: one for a state with low income, high income growth, low fertility, and low female labor participation; and the other for a state with high income (low income growth or no income growth), high fertility and high female labor participation. Finally, the dynamics converges to the steady state, which shows high fertility and high female labor participation even if the fertility and female labor participation are low in an initial period.

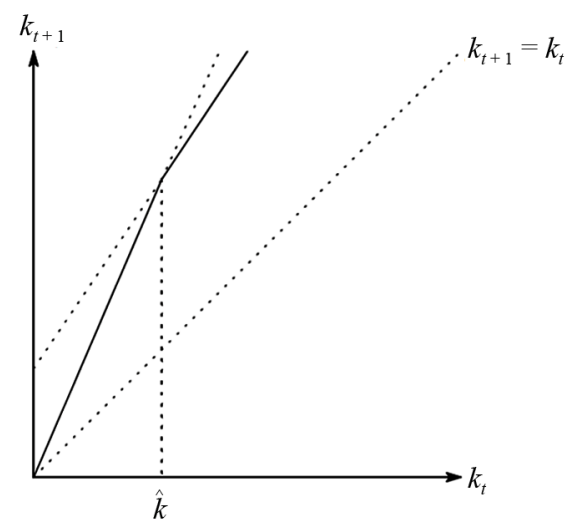

(a)

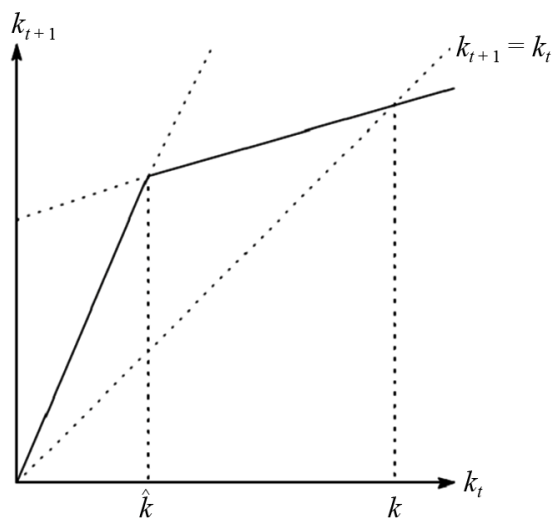

(b)

Figure 5. (a) Steady state with income growth; (b) Steady state with constant income.
In $k_{t}<\hat{k}_{t}$, fertility, female labor participation and income per capita are low. However, capital accumulation raises $k_{t}$ and $k_{t}$ is higher than $\hat{k}_{t}$. Then, fertility, female labor participation, and income per capita are higher than the state of $k_{t}<\hat{k}_{t}$. This result shows a positive correlation between fertility and female labor participation, and between fertility and income per capita. Although this result is consistent with the child-care service model (Apps and Rees (2004) [7] and Martínez and Iza (2004) [9]), this paper expands Apps and Rees (2004) [7] to a dynamic general equilibrium model and simplifies Martínez and Iza (2004) [9].

\section{Child-Care Policy Analysis}

This section presents an examination of how child-care policies of two types affect fertility: one for child allowance and the other for subsidy for child-care services. First, we examine the effect of a child allowance.

\subsection{Child Allowance}

We consider a child allowance policy wherein an allowance is given to households in direct relation to the number of children they have. The allowance decreases the net child-care cost per child. Assuming that the allowance is financed by a lump-sum tax, then the budget constraint for a no use child-care service is shown as follows ${ }^{18}$

$$
(\hat{z}-\hat{q}) w_{t} n_{t}+c_{1 t}+\frac{c_{2 t+1}}{1+r_{t+1}}=\left(1-\phi n_{t}\right) w_{t}-T_{t}
$$

Therein, $\hat{q} w_{t}$ is given for a child, where $\hat{q}$ is the constant subsidy rate, assumed as $\hat{z}-\hat{q}>0$ and $0<\hat{q}<1^{19}$. With a balanced budget, the lump-sum tax $T_{t}$ is determined as

$$
T_{t}=\hat{q} w_{t} n_{t}
$$

Each household maximizes its utility (4) under the budget constraint (25). In addition, considering (26), fertility $n_{t}^{\text {no }}$ and saving $s_{t}$ are given as

$$
\begin{aligned}
n_{t}^{\text {no }} & =\frac{1-\alpha-\beta}{\hat{z}-(\alpha+\beta) \hat{q}+\phi}, \\
s_{t} & =\beta\left(1-\hat{q} n_{t}^{\text {no }}\right) w_{t}
\end{aligned}
$$

Child allowance $\hat{q}$ always pulls up the fertility $n_{t}^{\text {no }}$, as shown by (27). With (14), (27), and (28) and capital market equilibrium condition $k_{t+1}=s_{t} / n_{t}$, we obtain the

\footnotetext{
${ }^{18}$ This section assumes a lump-sum tax. For example, we consider taxation of another type-a payroll tax. A payroll tax affects the household's decision to have children through a decrease in the opportunity cost to have children. Then, the policy effect contains not only child allowance effects but also taxation effects. This section uses a lump-sum tax to present a pure policy effect.

${ }^{19}$ This paper assumes income proportional to the child allowance. The reason is to maintain an appropriate level of child allowance even if an increase in the wage rate $w_{t}$ pulls up child-care cost $z$.
} 
following difference equation for $k_{t}$ :

$$
\begin{gathered}
k_{t+1}=\frac{\beta(\hat{z}+\phi-\hat{q})}{1-\alpha-\beta} \frac{\omega}{b} \frac{\hat{z}-(\alpha+\beta) \hat{q}+\phi}{\hat{z}+(\alpha+\beta)(\varphi-\hat{q})} k_{t} \\
g_{t}=\frac{\beta(\hat{z}+\phi-\hat{q})}{1-\alpha-\beta} \frac{\omega}{b} \frac{\hat{z}-(\alpha+\beta) \hat{q}+\phi}{\hat{z}+(\alpha+\beta)(\phi-\hat{q})}
\end{gathered}
$$

By total differentiation with respect to $\hat{q}$ at the approximation of $\hat{q}=0$, we obtain

$$
\frac{d k_{t+1}}{d \hat{q}}=-\frac{\beta}{1-\alpha-\beta} \frac{\omega}{b} \frac{(\hat{z}+\phi)\left(\hat{z}+(\alpha+\beta)^{2} \phi\right)}{(\hat{z}+(\alpha+\beta) \phi)^{2}}<0 .
$$

Therefore, the child allowance decreases capital per capita in the subsequent period $k_{t+1}$, in addition to income growth rate $g_{t}$. Because of the child allowance, income per capita continues decreasing to zero if the income growth rate $g_{t}$ is less than one.

We consider the effect of a child allowance in the case in which households use child-care services. Then, the budget constraint is shown as follows

$$
(\hat{z}-\hat{q}) w_{t} n_{t}+p n_{t}+c_{1 t}+\frac{c_{2 t+1}}{1+r_{t+1}}=w_{t}-T_{t}
$$

Each household maximizes its utility (4) under budget constraint (32). Considering (26), fertility $n_{t}^{\text {care }}$ and saving $s_{t}$ are given as

$$
\begin{gathered}
n_{t}^{\text {care }}=\frac{1-\alpha-\beta}{\hat{z}-(\alpha+\beta) \hat{q}+\frac{b p}{\omega k_{t}},} \\
s_{t}=\beta\left(1-\hat{q} n_{t}^{\text {care }}\right) w_{t}
\end{gathered}
$$

Child allowance $\hat{q}$ increases fertility $n_{t}^{\text {care }}$ for any $k_{t}$. However, in the steady state, the child allowance does not always increase fertility. With (14), (33), (34) and capital market equilibrium condition $k_{t+1}=s_{t} / n_{t}$, we obtain the following difference equation for $k_{t}$ :

$$
=\frac{\beta}{1-\alpha-\beta} \frac{(\hat{z}-\hat{q}) k_{t}+\frac{b p}{\omega}}{(\hat{z}-(\alpha+\beta) \hat{q}) k_{t}+\frac{b p}{\omega}}\left(p+\frac{(\hat{z}-\hat{q}) \omega}{b} k_{t}\right) \text {. }
$$

By total differentiation with respect to $\hat{q}$ at the approximation of $\hat{q}=0$, we obtain

$$
\begin{aligned}
& \frac{d k_{t+1}}{d \hat{q}} \\
= & -\frac{\beta}{1-\alpha-\beta}\left(\frac{(1-\alpha-\beta)\left(p+\frac{\hat{z} \omega}{b} k_{t}\right)}{\hat{z} k_{t}+\frac{b p}{\omega}}+\frac{\omega}{b}\right) k_{t}<0 .
\end{aligned}
$$

Child allowance $\hat{q}$ decreases capital-per-capita $k_{t+1}$ for any $k_{t}$. Considering $g=k_{t+1} / k_{t}$ in $k_{t} \rightarrow \infty$,

$$
g=\frac{\beta}{1-\alpha-\beta} \frac{(\hat{z}-\hat{q})^{2} \omega}{b(\hat{z}-(\alpha+\beta) \hat{q})}
$$

By total differentiation with respect to $\hat{q}$ at the approximation of $\hat{q}=0$,

$$
\frac{d g}{d \hat{q}}=-\frac{\beta}{1-\alpha-\beta} \frac{\omega(2-\alpha-\beta)}{b}<0 .
$$

The child allowance decreases the income growth rate. Income growth ceases and converges to the steady state specified by $k_{t+1}=k_{t}=k$ if the income growth rate is less than one in $k_{t} \rightarrow \infty$ because of the child allowance. If income growth continues with the child allowance at the steady state, then the fertility is

$$
n_{\mathrm{t}}^{\text {care,growth }}=\frac{1-\alpha-\beta}{\hat{z}-(\alpha+\beta) \hat{q}} .
$$

The child allowance increases the fertility in income growth. However, in the steady state defined as $k_{t+1}=k_{t}=$ $k$, the fertility is not always increased by the child allowance. In this steady state, $k$ and $n^{\text {care, no growth }}$ are shown as

$$
\begin{gathered}
k=\frac{(\hat{z}-\hat{q}) k+\frac{b p}{\omega}}{(\hat{z}-(\alpha+\beta) \hat{q}) k+\frac{b p}{\omega}}\left(p+\frac{(\hat{z}-\hat{q}) \omega}{b} k\right), \\
n^{\text {care,nogrowth }}=\frac{1-\alpha-\beta}{\hat{z}-(\alpha+\beta) \hat{q}+\frac{b p}{\omega k}} .
\end{gathered}
$$

The capital per capita in the steady state $k$ is uniquely determined. By total differentiation with respect to $\hat{q}$ at the approximation of $\hat{q}=0$,

$$
\frac{d k}{d \hat{q}}=-\frac{2 p+\left(\alpha+\beta-\frac{2 \hat{z}}{b}\right) k}{\hat{z}-\frac{\hat{z}^{2}}{b}+\frac{b p^{2}}{\omega k^{2}}} .
$$

Considering $d k_{t+1} / d \hat{q}<0$ for any $k_{t}, d k / d \hat{q}<0$ holds clearly $^{20}$. Then, we obtain

$$
\frac{d n}{d \hat{q}}=\frac{(1-\alpha-\beta)\left(\alpha+\beta+\frac{b p}{\omega k^{2}} \frac{d k}{d \hat{q}}\right)}{\left(\hat{z}+\frac{b p}{\omega k}\right)^{2}}
$$

This sign is ambiguous. The child allowance pulls up the fertility because of $d n / d \hat{q}>0$ if $d k / d \hat{q}>-\omega k^{2}(\alpha+\beta) / b p$. Finally, the child allowance affects $\hat{k}$ as

\footnotetext{
${ }^{20}$ Figure 6(b) depicts $d k / d \hat{q}<0$.
} 


$$
\frac{d \hat{k}}{d \hat{q}}=-\frac{b p(1-\alpha-\beta)(\alpha+\beta)}{\omega(\hat{z}+\phi)^{2}}<0 .
$$

Figure 6 depicts the effects of a child allowance on the dynamics of $k_{t}$.

Then, the following proposition is established.

\section{Proposition 3}

The child allowance decreases the income growth rate or income level. Given continued income growth, the child allowance pulls up fertility. Otherwise, the child allowance does not always pull up fertility.

We should consider the effects of child allowance on the fertility in both (39) and (41). If the fertility is given as (41), then the income converges to a steady state income. Then, the child allowance pulls up fertility in the short run. However, in the long run, a decrease in capital per capita caused by an increase in fertility diminishes income per capita. This income decrease has negative effects on fertility. Therefore, the child allowance does not always increase fertility in the long run. This result is fundamentally equivalent to that obtained by Fanti and Gori $(2009)^{21}$. However, the fertility is given by (39) in continued income growth, child allowance can always pull

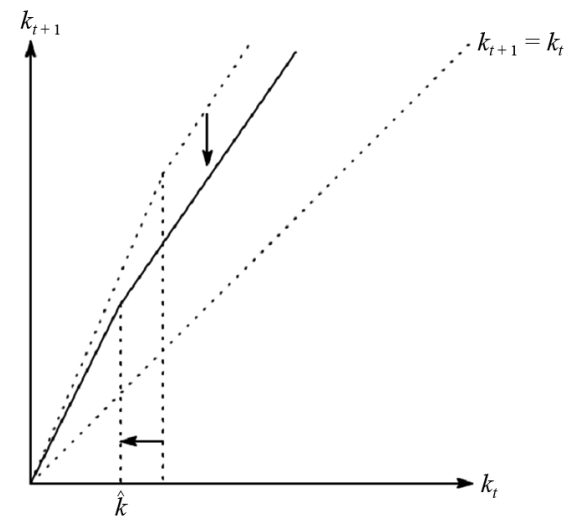

(a)

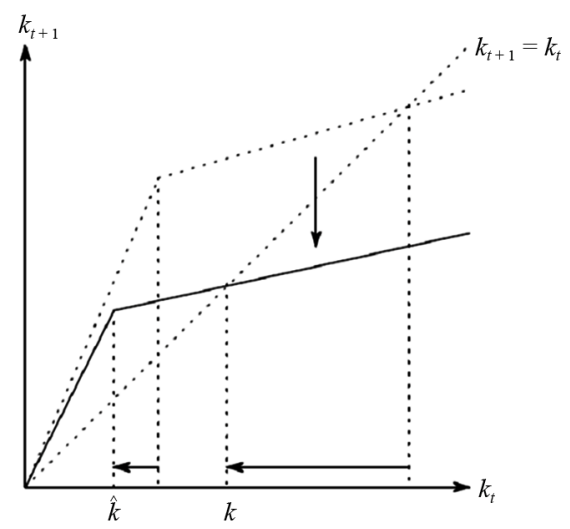

(b)

Figure 6. (a) Child allowance in the steady state with income growth; (b) Child allowance in the steady state with constant income. up the fertility ${ }^{22}$. This proposition, which hinges upon whether a child allowance can always increase the fertility, depends on income growth. van Groezen, Leers, and Meijdam (2003) [19] derived positive child allowance effects on the fertility in a small open economy. van Groezen and Meijdam (2008) [20] examined the child allowance in a closed economy with the pay-as-you-go pension and derived the optimal child allowance. In van Groezen and Meijdam (2008) [20], introduction of the child allowance pulls up fertility. In contrast, this paper, which contains no externality as a pay-as-you-go pension, reports that introduction of a child allowance decreases fertility.

\subsection{Subsidy for Child-Care Service}

We consider a subsidy for child-care services whereby a subsidy is given to households in proportion to the number of children they have. This subsidy decreases the net child-care service cost per child. Assuming that the subsidy is financed by a lump-sum tax, the budget constraint for using child-care services is shown as follows

$$
\hat{z} w_{t} n_{t}+(p-v) n_{t}+c_{1 t}+\frac{c_{2 t+1}}{1+r_{t+1}}=w_{t}-T_{t}
$$

Therein, $\mathrm{v}$ is given for a child, where $v$ is constant and assumed $v<p$. With a balanced budget, the lump-sum $\operatorname{tax} T_{t}$ is determined as

$$
T_{t}=v n_{t}
$$

Each household maximizes its utility (4) under budget constraint (45). Considering (46), fertility $n_{t}^{\text {care }}$ and saving $s_{t}$ are given as

$$
\begin{array}{r}
n_{t}^{\text {no }}=\frac{1-\alpha-\beta}{\hat{z}+\frac{p-(\alpha+\beta) v}{w_{t}},} \\
s_{t}=\beta\left(w_{t}-v n_{t}^{\text {care }}\right)
\end{array}
$$

With (14), (47), and (48), in addition to capital market equilibrium condition $k_{t+1}=s_{t} / n_{t}$, we obtain the following difference equation for $k_{t}$ :

$$
k_{t+1}=\frac{\beta}{b} \frac{\hat{z} \omega k_{t}+b(p-(\alpha+\beta) v)}{1-\alpha-\beta}-\beta v
$$

By total differentiation with respect to $v$ at the approximation of $v=0$,

$$
\frac{d k_{t+1}}{d v}=-\frac{\beta}{1-\alpha-\beta}<0
$$

\footnotetext{
${ }^{21}$ Fanti and Gori (2009) examined a child tax that implies a negative child allowance and caused an increase in fertility.

${ }^{22}$ Zhang (1997) showed that the child allowance can increase the fertility in the quality and quantity of children model. This model considered human capital accumulation, which brings about income growth. However, our paper does not consider the quality of children.
} 
The subsidy for child-care services decreases $k_{t+1}$ for any $k_{t}$. We consider this policy effect in the steady state. First, we consider the steady state with continuing income growth. Then the income growth rate decreases, as derived by (50). The fertility denotes $n^{\text {care,growth }}=(1-\alpha-\beta) / \hat{z}$, which shows that the subsidy for child-care services exerts no effect on the fertility.

Second, we consider the steady state with constant capital-per-capita $k_{t+1}=k_{t}=k$. Then, the capital per capita in the steady state is

$$
k=\frac{\beta p-v(1-(1-\beta)(\alpha+\beta))}{1-\alpha-\beta-\frac{\omega \beta \hat{z}}{b}}
$$

A brief calculation derives $d k / d v<0$. The fertility in this steady state is

$$
=\frac{n^{\text {care,nogrowth }}}{\hat{z}+\frac{b(p-(\alpha+\beta) v)}{\omega} \frac{1-\alpha-\beta}{\beta p-v(1-(1-\beta)(\alpha+\beta))}}
$$

By total differentiation with respect to $v$ at the approximation of $v=0$,

$$
\frac{d n^{\text {care,nogrowth }}}{d v}=\frac{\beta \omega^{2}}{b^{2} p}\left(\hat{z}-\frac{(1-\alpha-\beta) b}{\beta \omega}\right)<0 .
$$

The subsidy for child-care services decreases fertility because $\hat{z}<(1-\alpha-\beta) b /(\beta \omega)$. Consequently, the following proposition is established.

\section{Proposition 4}

Subsidies for child-care services decrease the income growth rate or income level. This policy exerts no effect on the fertility in the steady state with continuing income growth. This policy decreases fertility in the steady state with a constant income level.

Subsidies for child-care services decrease $\hat{k}$ because of $\hat{k}=b(p-v)(\hat{z}+(\alpha+\beta) \phi) /(\omega \varphi(\hat{z}+\phi))$ as presented in Figure 7.

Subsidies for child-care services can not pull up fertility in the long run even if subsidies can increase the fertility for any $k_{t}$ in the short run. The fertility $n^{\text {care, growth }}$ in income growth continuing is independent of this subsidy. However, the fertility (52) is decreased by this subsidy in the steady state. Therefore, it is important to consider whether income growth continues or not in the long run if we examine child allowance or subsidy for child-care services. Figure $\mathbf{3}$ presents a positive correlation between the fertility and the magnitude of governmental family policy. The result presented in this paper is consistent with the positive relation as Figure $\mathbf{3}$ in the short run. However, we do not always obtain a positive correlation in the long run.

In the following section, we assume that the child-care service fee and subsidy for child-care services are wageproportional.

\section{Discussion}

This paper assumes constant child-care service fee $p$. However, Lundholm and Ohlsson (1998) [36] considered a wage-proportional child-care service fee. This section assumes child-care service fee as a constant fraction of the wage rate and examines how both fertility and income growth rate are determined. We assume that it costs $\hat{c} w_{t}$ units of final goods to provide child-care services for each child. Considering profit maximization, we obtain $p=\hat{c} w_{t}$. With $\phi>\hat{c}$, households use child-care services. It depends on the parametric condition, not capital accumulation, whether households use child-care services or not. This differs greatly from the result in that child-care service fees are constant as Apps and Rees (2004) [7] and Martínez and Iza (2004) [9] assumed. Therefore, how child-care service fees are determined affects the dynamics of capital accumulation.

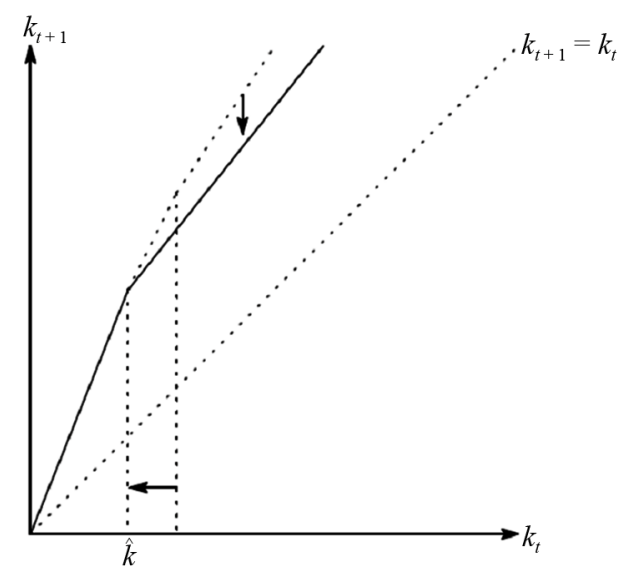

(a)

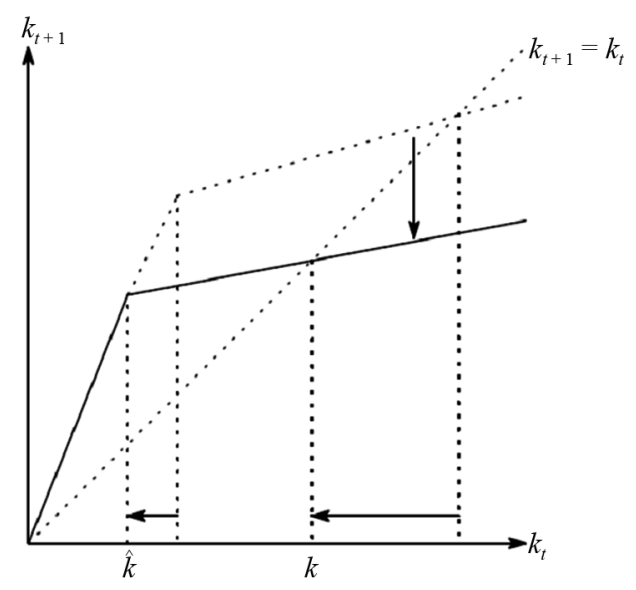

(b)

Figure 7. (a) Subsidy for child-care service in a steady state with income growth; (b) Subsidy for child-care service in a steady state with constant income. 
With $p=\hat{c} w_{t}$, the fertility and the saving given by (33) and (34), respectively, are shown as

$$
\begin{gathered}
n=\frac{1-\alpha-\beta}{\hat{z}+\hat{c}-(\alpha+\beta) \hat{q}} \\
s_{t}=\left(1-\frac{\hat{q}(1-\alpha-\beta)}{\hat{z}+\hat{c}-(\alpha+\beta) \hat{q}}\right) w_{t}
\end{gathered}
$$

Then, considering capital market equilibrium $n_{t} k_{t+1}=s_{t}$, the income growth rate is derived as shown below:

$$
g=\frac{\beta \omega}{b} \frac{\hat{z}+\hat{c}-\hat{q}}{1-\alpha-\beta} .
$$

Comparing (27) with (54), the fertility of (54) is larger than that of (27). In addition, comparing (30) with (56), the income growth rate of (56) is lower than that of (30). Therefore, the fertility with child-care services is larger than the case of no child-care services, whereas the income growth rate decreases. An increase in the fertility and a decrease in the income growth rate caused by child-care services do not depend on whether child-care service fees are fixed or wage-dependent.

Considering (54) and (56), an increase in the child allowance $\hat{q}$ increases the fertility although the income growth rate decreases. If the subsidy for child-care services is $v=\hat{v} w_{t}(\hat{v}>0)$, then the fertility of (47) changes to

$$
n=\frac{1-\alpha-\beta}{\hat{z}+\hat{c}-(\alpha+\beta) \hat{v}}
$$

Then, the subsidy for child-care services increases the fertility as the child allowance.

\section{Conclusions}

This paper presents analysis of how fertility is determined and affected by child-care services in a dynamic general equilibrium model under the assumption that complete substitution exists between individual child-care time and child-care services. Among the results presented herein, the following are most noteworthy.

When child-care services exist, one of two multiple states results: one for a state with low fertility, low female labor participation, low income level, and high income growth; and the other for a state with high fertility, high female labor participation, and low income growth or high income level with no income growth. Even if the amount of capital per capita is low in the initial period, income per capita increases; finally, the dynamics converge to the steady state with high fertility and high female labor participation as a result of capital accumulation. The result described in this paper is consistent with the positive correlation in developed countries. This paper sets the dynamic general equilibrium model as simply as possible and derives the positive correlation. In the latter part of this paper, we analyzed whether child-care policies, (e.g., a child allowance policy, wherein households receive an allowance in direct relation to the number of children they have, and the subsidy for child-care services policy) can raise the fertility rate. These policies can raise the fertility rate in the short run. However, the effect in the long run might differ. Because of the decrease in income with a decrease in capital per capita, the child allowance does not always increase fertility. If the income level converges to a constant income level in the long run, the child allowance can not always pull up the fertility. However, if income growth continues in the long run, then the child allowance can pull up the fertility in the long run. Therefore, the effect of child allowance on the fertility depends on whether income growth ceases or continues in the long run. Results show that the effect in the short run is consistent with the positive correlation between fertility and the magnitude of governmental family policy.

The model in this paper is consistent with the three positive correlations described for developed countries: 1) Fertility and female labor participation; 2) Fertility and income per capita; and 3) Fertility and the magnitude of governmental family policy. In addition, this paper presents a proposal that, before implementing child-care policies, the government should consider their short-run and long-run effects.

\section{Acknowledgements}

This paper was presented at the 66th Annual Congress of the International Institute of Public Finance (IIPF 2010) and the Far Eastern and South Asian Meeting of the Econometric Society 2008 (FEMES 2008). We would like to thank Akiyoshi Furukawa, Egbert Jongen, Shoji Katagiri, Hideaki Murase, Tamotsu Nakamura, Hikaru Ogawa, Takashi Oshio, Keiko Shimono, Ken Tabata, Hideki Toya, Stanley Winer, Akira Yakita and the seminar participants at Kobe University, Chuo University, Nagoya City University, IIPF 2010, FEMES 2008 and the 2008 Spring Meeting of the Japanese Economic Association. The research for this paper was financially supported in part by the Kobe University 21st Century COE program of the Ministry of Education, Culture, Sports, Science and Technology, a grant from the University of Kitakyushu, and Grants-in-Aid for Scientific Research (No. 19530237, No. 21730159, No. 23730283) for the first author.

\section{REFERENCES}

[1] N. Ahn and P. Mira, "A Note on the Changing Relationship between Fertility and Female Employment Rates in Developed Countries," Journal of Population Economics, Vol. 15, 2002, pp. 667-682. doi:10.1007/s001480100078

[2] J. E. Sleebos, "Low Fertility Rates in OECD Countries: 
Facts and Policy Responses,” OECD Social, Employment and Migration Working Papers, Vol. 15, 2003. http://www.oecd.org/dataoecd/13/38/16587241.pdf

[3] K. Yamaguchi, "On the Genuine Relationships between Female Labor Participation and Fertility: Investigations of OECD Countries (in Japanese)," RIETI Discussion Paper Series, 05-J-036, 2005.

http://www.rieti.go.jp/jp/publications/dp/05j036.pdf

[4] T. Kögel, "Did the Association between Fertility and Female Employment within OECD Countries Really Change in Sign?” Journal of Population Economics, Vol. 17, 2004, pp. 45-65. doi:10.1007/s00148-003-0180-z

[5] H. Engelhardt and A. Prskawetz, "On the Changing Correlation between Fertility and Female Employment over Space and Time,” European Journal of Population, Vol. 20, 2004, pp. 35-62. doi:10.1023/B:EUJP.0000014543.95571.3b

[6] O. Galor and D. Weil, "The Gender Gap, Fertility, and Growth,” American Economic Review, Vol. 86, No. 3, 1996, pp. 374-387. http://www.jstor.org/stable/2118202

[7] P. Apps and R. Rees, "Fertility, Taxation and Family Policy,” Scandinavian Journal of Economics, Vol. 106, No. 4, 2004, pp. 745-763. doi:10.1111/j.0347-0520.2004.00386

[8] M. Hirazawa and A. Yakita, "Fertility, Child Care outside the Home, and Pay-As-You-Go Social Security," Journal of Population Economics, Vol. 22, No. 3, 2009, pp. 565583. doi:10.1007/s00148-007-0153-8

[9] D. F. Martínez and A. Iza, "Skill Premium Effects on Fertility and Female Labor Force Supply,” Journal of Population Economics, Vol. 17, 2004, pp. 1-16. doi:10.1007/s00148-003-0150-5

[10] M. Yasuoka, “A Relationship between Fertility and Income (in Japanese),” The Society for Economic Studies, The University of Kitakyushu Working Paper Series, No. 2008-4, 2008

http://www.kitakyu-u.ac.jp/economy_new/research/files/y asuoka2008_2.pdf

[11] M. Momota, “The Gender Gap, Fertility, Subsidies and Growth,” Economics Letters, Vol. 69, 2000, pp. 401-405. doi:10.1016/S0165-1765(00)00304-9

[12] M. Yasuoka, "A Study of Childcare Support Policy in the Model Based on Endogenous Introduced the Childcare Goods Provided Publicly (in Japanese)," Quarterly of Social Security Research, Vol. 43, No. 3, 2007, pp. 261-274. http://www.ipss.go.jp/syoushika/bunken/data/pdf/186244 08.pdf

[13] L. W. Aarssen, "Why Is Fertility Lower in Wealthier Countries? The Role of Relaxed Fertility-Selection," Population and Development Review, Vol. 31, No. 1, 2005, pp. 113-126. http://www.jstor.org/stable/i278908 doi:10.1111/j.1728-4457.2005.00054.x

[14] G. S. Becker, “An Economic Analysis of Fertility,” In: A. Coale, Ed., Demographic and Economic Change in Developed Countries, Princeton University Press, Princeton, 1960.

[15] G. S. Becker, K. M. Murphy and R. Tamura, "Human Capital, Fertility, and Economic Growth,” Journal of Po- litical Economy, Vol. 98, No. 5, 1990, pp. S12-S37. http://www.jstor.org/stable/2937630 doi:10.1086/261723

[16] D. de la Croix and M. Doepke, "Inequality and Growth: Why Differential Fertility Matters?” American Economic Review, Vol. 93, No. 4, 2003, pp. 1091-1113. http://www.jstor.org/stable/3132280 doi: $10.1257 / 000282803769206214$

[17] M. Kimura and D. Yasui, "Public Provision of Private Child Goods," Journal of Public Economics, Vol. 93, 2009, pp. 741-751. doi:10.1016/j.jpubeco.2009.02.002

[18] T. Oshio, "Child-Care Reform in Pension System and the Fertility Rate (in Japanese)," Quarterly of Social Security Research, Vol. 36, No. 4, 2001, pp. 535-546. http://www.ipss.go.jp/syoushika/bunken/data/pdf/151581 07.pdf

[19] B. van Groezen, T. Leers and L. Meijdam, "Social Security and Endogenous Fertility: Pensions and Child Allowance as Siamese Twins," Journal of Public Economics, Vol. 87, 2003, pp. 233-251. doi:10.1016/S0047-2727(01)00134-7

[20] B. van Groezen and L. Meijdam, “Growing Old and Staying Young: Population Policy in an Ageing Closed Economy," Journal of Population Economics, Vol. 21, No. 3, 2008, pp. 573-588. doi:10.1007/s00148-006-0067-x

[21] L. Fanti and L. Gori, "Population and Neoclassical Economic Growth: A New Child Policy Perspective,” Economics Letters, Vol. 104, 2009, pp. 27-30. doi:10.1016/j.econlet.2009.03.014

[22] P. McDonald, "Low Fertility and the State: The Efficacy of Policy,” Population and Development Review, Vol. 32, No. 3, 2006, pp. 485-510. http://www.jstor.org/stable/i20058896 doi:10.1111/j.1728-4457.2006.00134.X

[23] W. Lutz, “Will Europe Be Short of Children?” Family Observer, European Observatory on Family Matters, European Commission, 1999, pp. 8-16.

[24] K. Milligan, “Quebec’s Baby Bonus: Can Public Policy Raise Fertility?” Backgrounder, C.D. Home Institute, Toronto, 2002.

[25] G. Laroque and B. Salanie, "Does Fertility Respond to Financial Incentives?” CEPR Discussion Paper Series, No. 5007, Center for Economic Policy Research, London, 2005.

[26] J. Zhang, "Fertility, Growth and Public Investments in Children,” Canadian Journal of Economics, Vol. 30, No. 4a, 1997, pp. 835-843. http://www.jstor.org/stable/i301038 doi:10.2307/136272

[27] B. van Praag and M. Warnaar, "The Cost of Children and the Use of Demographic Variables in Consumer Demand,” In: M. Rosenzweig and O. Stark, Eds., Handbook of Population and Family Economics, Elsevier Science, Amsterdam, 1997. doi:10.1016/S1574-003X(97)80023-2

[28] Z. Eckstein and K. I. Wolpin, "Endogenous Fertility and Optimal Population Size,” Journal of Public Economics, Vol. 27, 1985, pp. 93-106. doi:10.1016/0047-2727(85)90030-1

[29] B. U. Wigger, "Pay-As-You-Go Financed Public Pensions in a Model of Endogenous Growth and Fertility," 
Journal of Population Economics, Vol. 12, No. 4, 1999, pp. 625-640. doi:10.1007/s001480050117

[30] P. M. Romer, "Increasing Returns and Long Run Growth," Journal of Political Economy, Vol. 94, No. 5, 1986, pp. 1002-1037. http://www.jstor.org/stable/1833190 doi:10.1086/261420

[31] E. Grossman and N. Yanagawa, "Asset Bubbles and Endogenous Growth,” Journal of Monetary Economics, Vol. 31, No. 1, 1993, pp. 3-19. doi:10.1016/0304-3932(93)90014-7

[32] M. Yasuoka and A. Miyake, "Change in the Transition of the Fertility Rate,” Economics Letters, Vol. 106, No. 2, 2010, pp. 78-80. doi:10.1016/j.econlet.2009.10.005

[33] G. S. Becker and R. J. Barro, "A Reformulation of the Economic Theory of Fertility," Quarterly Journal of Eco- nomics, Vol. 103, No. 1, 1988, pp. 1-25. doi: $10.2307 / 1882640$

[34] R. J. Barro and G. S. Becker, "Fertility Choice in a Model of Economic Growth,” Econometrica, Vol. 57, No. 2, 1989, pp. 481-501. http://www.jstor.org/stable/i332736 doi: $10.2307 / 1912563$

[35] P. Wang, C. K. Yip and C. A. Scotese, "Fertility Choice and Economic Growth: Theory and Evidence," Review of Economics and Statistics, Vol. 76, No. 2, 1994, pp. 255266. http://www.jstor.org/stable/i336980 doi:10.2307/2109880

[36] M. Lundholm and H. Ohlsson, "Wages, Taxes and Publicly Provided Day Care,” Journal of Population Economics, Vol. 11, 1998, pp. 185-204.

doi:10.1007/s001480050064 